\title{
Correction to: Nexus between vulnerability and adaptive capacity of drought-prone rural households in northern Bangladesh
}

\section{Roquia Salam ${ }^{1}$ - Abu Reza Md. Towfiqul Islam ${ }^{1}$ (D) Badhon Kumar Shill ${ }^{1}$.} G. M. Monirul Alam ${ }^{2,3} \cdot$ Md. Hasanuzzaman $^{1} \cdot$ Md. Morshadul Hasan ${ }^{4}$. Sobhy M. Ibrahim ${ }^{5} \cdot$ Roger C. Shouse ${ }^{6}$

Published online: 22 January 2021

(c) Springer Nature B.V. 2021

\section{Correction to: Natural Hazards https://doi.org/10.1007/s11069-020-04473-z}

The article was published with a spelling error in one of the co-author names. The correct spelling is reflected in this correction and the original work has been updated to reflect the correct spelling of the name as Md. Morshadul Hasan. The original article has been corrected.

Publisher's Note Springer Nature remains neutral with regard to jurisdictional claims in published maps and institutional affiliations.

The original article can be found online at https://doi.org/10.1007/s11069-020-04473-z.

Abu Reza Md. Towfiqul Islam

towfiq_dm@brur.ac.bd

G. M. Monirul Alam

gmmonirul79@gmail.com

1 Department of Disaster Management, Begum Rokeya University, Rangpur 5400, Bangladesh

2 Department of Agribusiness, Bangabandhu Sheikh Mujibur Rahman Agricultural University, Gazipur, Bangladesh

3 School of Commerce, University of Southern Queensland, Melbourne, Australia

4 School of Management, University of Science and Technology of China, Hefei 230026, Anhui, China

5 Department of Biochemistry, College of Science, King Saud University, P.O. Box: 2455, Riyadh 11451, Saudi Arabia

6 Program in Public Administration, Sichuan University, Chengdu, China 